\title{
Translation and validation of revised illness perception questionnaire (IPQ-R): The Malay version in Malaysia
}

\author{
Sherene Tan Su Ann ${ }^{1}$, Shamila Balasubramaniam ${ }^{2}$, Tye Sok $\mathrm{Cin}^{3}$ and Balamurugan Tangiisuran ${ }^{4 *}$ \\ ${ }^{1}$ Department of Pharmacy, Penang General Hospital, Pulau Pinang, Malaysia \\ ${ }^{2}$ School of Pharmaceutical Sciences, Universiti Sains Malaysia, 11800 USM, Pulau Pinang, Malaysia \\ ${ }^{3}$ Department of Clinical Pharmacy and Pharmacology, University of Groningen, University Medical Center Groningen, Groningen, The Netherlands \\ ${ }^{4}$ National Poison Centre and School of Pharmaceutical Sciences Universiti Sains Malaysia, 11800 USM, Penang, Malaysia
}

\begin{abstract}
Introduction: Patients' perceptions are critical determinants in healthcare acquisition. This study aims to translate the Revised Illness Perception Questionnaire (IPQ-R) into the Malay version and further validate it among patients with atrial fibrillation in a tertiary care center.

Methods: A standard "forward-backward" procedure was used to translate IPQ-R into the Malay language and further validated using a convenience sample of 62 atrial fibrillation patients. Reliability and validity were tested via internal consistency and test-retest method.

Results: Internal consistency using the Cronbach's Alpha test of the dimensions of IPQ-R ranged from 0.50 to 0.87 and test-retest reliability using Spearman's Rank Correlation Coefficient ranged from 0.86 to $0.98(p<0.001)$. There was no relationship found between warfarin adherence and atrial fibrillation perception in this study. However, there is a positive correlation between patients' INR and the negative emotions triggered by AF.

Conclusion: The translated Malay version of the Revised-Illness Perception Questionnaire (IPQ-R) represents a valid and reliable instrument enabling a quantitative assessment of illness beliefs among AF patients in Malaysia.
\end{abstract}

\section{Introduction}

Atrial fibrillation (AF) is the most common type of cardiac arrhythmia characterized by disorganized electrical signalling within the cardiac atria, resulting in an increased and irregular heartbeat [1]. $\mathrm{AF}$ is associated with a high risk of thromboembolic events such as stroke, congestive heart failure and other hemodynamic compromise [2]. AF prevalence increases with advancing age, with approximately $1 \%$ of AF patients being less than 60 years old, whereas up to $12 \%$ of patients are between 75 to 84 years old [3]. In developed countries like the United States, hospitalizations with AF as the primary diagnosis exceed 460000 cases each year and it is estimated that over 80000 annual deaths were contributed by AF [4]. In Malaysia, studies revealed that the prevalence of $\mathrm{AF}$ among patients admitted to Malaysian hospitals was $2.80 \%$ [5] meanwhile in the community it was $0.54 \%$ [6]. Previous literature has indicated that emotional distress among patients with newly diagnosed or recurrent AF contributes to reduced physical and mental health-related quality of life (HRQoL) among these patients [7-9].

Illness perception is the reflection of individuals' beliefs and expectations related to a disease or its manifestations [10]. The Illness Perception Questionnaire (IPQ) was first developed by Weinman et al in 1996 to provide a quantitative assessment of illness representation based on Leventhal's Self-Regulatory Model [11]. In the model, it was hypothesized that, when people are confronted with illness or other health threats, the cognitive and emotional components are involved simultaneously [12]. The cognitive model composed of individual beliefs, interpretations, emotional and behavioural components, is strongly associated with treatment and attitude control which would ultimately determine an individual's understanding of their disease state, the style of coping and their health related quality of life [13]. Several studies have shown that patients' perceptions and preferences are important factors which influence their decision to receive, decline or comply with medication therapy [14-16]. In 2011, McCabe, et al. conducted a descriptive, cross sectional study using 207 subjects to describe illness beliefs among patients with recurrent symptomatic AF and describe the relationships among illness beliefs [17]. Their subjects perceived $\mathrm{AF}$ as a chronic and unpredictable condition with serious consequences. They found that relationship between AF illness beliefs and negative emotion suggests that assessment of illness beliefs can identify patients who are at risk for psychological distress. Therefore, it would allow the planning of suitable interventional strategies which could in turn contribute to positive health outcomes.

Since patients' perceptions towards their illness are crucial in ensuring medication adherence and achieving their optimum health, there is a need for a reliable and validated instrument to assess illness perceptions. The initial IPQ comprises five components which describe the cognitive representation of illness, namely identity, cause, timeline, consequences and cure control [18]. Weaknesses of the IPQ, such as discrepancies in the internal consistency, were discovered from

*Correspondence to: Balamurugan Tangiisuran, National Poison Centre, Universiti Sains Malaysia, USM 11800 Penang, Malaysia, E-mail: bala@usm.my

Key words: illness perception, translation, malay

Received: January 15, 2019; Accepted: January 31, 2019; Published: February 04,2019 
the accumulated experience of researchers. Thus, the Revised Illness Perception Questionnaire (IPQ-R) was then developed in 2002 by Moss-Morris and colleagues [19]. The cure control and timeline dimensions were separated into two separate dimensions each: cure control and treatment control; and timeline component and timeline cyclical component. The emotional dimension was added to provide an assessment of the emotional responses generated by the illness. Moss-Morris et al also incorporated the illness coherence dimension to investigate patients' understanding of their illness.

In order to capture our true population's perceptions regarding their illness, a Malay language version of the IPQ-R is needed. Hence, the principal objective of this study is to translate and examine the psychometric properties of the Malay version of the IPQ-R among patients with atrial fibrillation. This will pave the way for more studies to be done in Malaysia on patients' perceptions towards their illness, factors affecting patients' perceptions, and hopefully, clinical outcomes among patients can be improved.

\section{Materials and methods}

This was a prospective, survey-based observational study conducted among AF patients who were attending regular follow up at the INR clinic of either the cardiothoracic, cardiology or outpatient department in Penang General Hospital, which is a tertiary hospital and referral center for the northern region of Peninsula Malaysia. Recruitment was based on convenient sampling recruitment, which took place for a month in April 2014. This study was compliant to Good Clinical Practice and was submitted the Malaysian Research and Ethics Committee for approval, with the approval number NMRR-14221-19768.

\section{Participants}

Patients who fulfilled the criteria of having been followed up in the International Normalised Ratio (INR) clinic of either the cardiothoracic, cardiology or outpatient department in Penang Hospital, diagnosed with AF, under warfarin treatment, over 18 years of age and literate in the Malay language were invited to participate in this study. Patients with severe health problems (terminal illness, comatose or psychiatric illness) or cognitive impairment and could not complete interviews were excluded.

\section{Data collection procedures}

In the translation and adaptation of the IPQ- $\mathrm{R}$ into the Malay language, the standard four-step method known as the ForwardBackward Translation Procedure, as recommended by the WHO was used [20]. The services of a health professional, who was familiar with the terminology, as well as being a Malay language native speaker and fluent English speaker, were used. An English and Malay expert panel was set up by a designated editor-in-chief. The goal was to identify and resolve inadequate expressions/concepts and discrepancies of the translation. In the backward translation process, the questionnaire was translated back to English by an independent, professional translator who had no knowledge of the questionnaire.

Subsequently, a pre-test was conducted with the target population $(n=10)$. This pre-test included administration of the translated Malay IPQ-R and debriefing. In debriefing, respondents were asked on their thoughts about the questions. The debriefing questions were asked for each item in the questionnaire and then compared to the respondent's actual response. The final version of the Malay language IPQ-R developed was used for the reliability and validity study with
62 subjects. A face-to-face interview was conducted with each patient using the translated Malay IPQ-R version and the translated eight-item Morisky Medication Adherence Scale (MMAS-8). On the same day of the interview, medical records were reviewed and related data were collected in a validated data collection form.

\section{Test-retest reliability analysis}

Approximately one-fifth of these subjects $(n=13)$ were selected for a one-week reliability test-retest analysis. Face-to-face interview of the translated Malay-version IPQ-R was administered again to each subject.

\section{Instrument for data collection}

The three instruments used in this study for data collection were the translated Malay version IPQ-R, a previously translated and validated Malay language eight-item Morisky Medication Adherence Scale (MMAS-8) and a data collection form for medical record data collection.

The IPQ-R is a 70-item questionnaire, which comprises 9 dimensions; identity (14 items) and causal dimensions (18 items) are separated from the remaining dimensions (38 items).

I. Illness Identity - the number of symptoms the patient identifies as a symptom of the illness

II. Personal Control - The ability of the patient to exert personal control over the illness

III. Treatment Control - The effectiveness of the treatment to control or cure the illness

IV. Timeline (Acute/Chronic) - The acute versus chronic course of the illness

V. Timeline Cycle - The unpredictable nature or cyclical nature of the disease

VI. Consequences - The perceived impact or consequences of the illness on the patient

VII. Cause - The perceived cause of the illness

VIII. Illness Coherence - The perceived understanding and the ability to make sense of the illness

IX. Emotional representation - The emotions elicited by the illness

In all dimensions except the identity dimension, subjects were given 5 options which were converted to a 5 -point Likert type scale for results analysis: Strongly Disagree (1), Disagree (2), Neither Agree Nor Disagree (3), Agree (4) and Strongly Agree (5). For the identity dimension, 2 options were given: symptom attributed to $A F$ (1) and symptom not attributed to $A F(0)$. Higher scores for each dimension reflect stronger beliefs of the dimension being measured.

The original English version of the eight-item Morisky Medication Adherence Scale MMAS-8 was developed by Morisky, et al. in 2008 [21]. In this study, to measure compliance, the translated and validated Malaysian version of MMAS- 8 was used [22]. Total score of the MMAS- 8 ranges from $0.0-8.0$. Adherence level was divided into three categories: Low Adherence (Total score <6.0), Moderate Adherence (Total score 6.0 - 8.0) and High Adherence (Total score=8.0). The data collection form was reviewed and validated by two researchers related to the area of research. 


\section{Statistical analysis}

Statistical analysis was performed using SPSS software version 16. Descriptive data were used to describe patients' demographic information concurrent diseases, medications used, INR control and medication adherence levels. Percentages and frequencies were used for categorical variables while median was calculated for continuous variables. Spearman's rank correlation coefficient was used to evaluate associations between illness perception and INR; and illness perception and adherence score. Kruskal-Wallis and Mann-Whitney tests were used to evaluate the differences between illness perception and INR control; and illness perception and medication adherence levels.

The translated Malay-version IPQ-R dimensions were validated using Cronbach's Alpha. The criterion for accepting Cronbach's alpha is a score above 0.50 . Test-retest reliability was determined using Spearman's Rank Correlation Coefficient and the correlations were interpreted with the following criteria: Any P-value $<0.05$ was considered as statistically significant in this study.

\section{Results}

The final analysis included 62 patients with AF, with 13 patients completing the test-retest reliability analysis. Twenty-seven (43.5\%) were Malays, followed by 25 (40.3\%) Chinese and 10 (16.1\%) Indians (Table 1). The mean age (years $\pm \mathrm{SD}$ ) of these patients were $62.8 \pm$ 10.7 and 35 (56.5\%) of them were males. Thirty-two (51.6\%) of them possessed at least secondary education level. Median duration of taking warfarin was 3.0 years with a median INR on the day of interview of 2.2. Forty-one (66.1\%) of them had their INR within range on the day of interview.

Among 62 subjects with AF, 16 (25.8\%), 25 (40.3\%) and 21 (33.9\%) were in the low, moderate and high adherence groups and they had a median MMAS-8 score of 7.0. The most common comorbidities in this sample of patients were hypertension (61.3\%), dyslipidemia (35.5\%) and diabetes (33.9\%). Other concurrent diseases (62.9\%) included valvular disease, thyroid disease, cancer, obesity and skin disease. The most common concurrent medications in this sample of patients were statins (79\%), beta-blockers (69.4\%) and ACE inhibitors (54.9\%).

\section{Reliability of IPQ-R dimensions}

\section{Internal consistency (Cronbach's Alpha)}

Cronbach's alpha ( $\alpha$ ) test of internal consistency ranged from 0.5 to 0.9 (Table 2). All dimensions were above 0.5 except the treatment control dimension $(\alpha=0.5)$. The highest Cronbach's alpha value obtained was from the emotional representation $(\alpha=0.9)$ dimension.

\section{Test-retest reliability}

The test-retest reliability using the Spearman's Rank Correlation Coefficient $\left(r_{s}\right)$ ranged from 0.9 to $1.0,(p<0.001)$ which exhibits excellent reliability and stability $\left(r_{s}>0.8\right)$. The highest Spearman's Rank Correlation Coefficient $\left(r_{s}\right)$ value obtained was from the timeline cycle $\left(r_{s}=1.0\right)$ dimension whereas the lowest was obtained from timeline (acute/chronic) $\left(r_{s}=0.9\right)$ dimension (Table 3$)$.

Differences between those with INR in range and those with INR out of range with regard to illness perception showed no significant difference in term of how the two groups view their illness. It was found that there was no association between patient's INR and illness perception except for a positive correlation $(\mathrm{r}=0.3, \mathrm{p}<0.05)$ in the emotional representation dimension (Table 4).
It was found that there was no significant difference between patients with low, moderate and high adherence with regard to illness perception. There was also no association between patient's MMAS-8 score and illness perception.

\section{Revised illness perception questionnaire (IPQ-R) total score}

In terms of identity dimension, our subjects identified 4 out of 14 symptoms as symptoms of their AF (Table 5). In terms of the cause of AF, patients reported stronger beliefs that their $\mathrm{AF}$ is due to accident or chance, followed by risk factors and lastly, psychological and immunity causes.

In the dimensions of personal control and treatment control, subjects' beliefs about how much they could personally control their

Table 1. Clinical and Demographic Data

\begin{tabular}{|c|c|}
\hline Characteristics & $\begin{array}{l}\text { No. of Patients (\%) } \\
\text { Total N = } 62\end{array}$ \\
\hline Age (years), mean \pm SD & $62.79 \pm 10.662$ \\
\hline \multicolumn{2}{|l|}{ Gender } \\
\hline Male & $35(56.5)$ \\
\hline Female & $27(43.5)$ \\
\hline \multicolumn{2}{|l|}{ Ethnicity } \\
\hline Malay & $27(43.5)$ \\
\hline Chinese & $25(40.3)$ \\
\hline Indian & $10(16.1)$ \\
\hline \multicolumn{2}{|l|}{ Education Level } \\
\hline Uneducated & $5(8.1)$ \\
\hline Primary & $16(25.8)$ \\
\hline Secondary & $32(51.6)$ \\
\hline Tertiary & $9(14.5)$ \\
\hline \multicolumn{2}{|l|}{ Clinic Follow-Up } \\
\hline Cardiothoracic & $14(22.6)$ \\
\hline Cardiology & $18(29.0)$ \\
\hline Outpatient Department & $30(48.4)$ \\
\hline Duration of taking Warfarin (years), median & 3.0 \\
\hline Current INR, median & 2.2 \\
\hline \multicolumn{2}{|l|}{ INR within range } \\
\hline Yes & $41(66.1)$ \\
\hline No & $21(33.9)$ \\
\hline \multicolumn{2}{|l|}{ Disease Counselling } \\
\hline Yes & $39(62.9)$ \\
\hline No & $23(37.1)$ \\
\hline \multicolumn{2}{|l|}{ Warfarin Counselling } \\
\hline Yes & $61(98.4)$ \\
\hline No & $1(1.6)$ \\
\hline MMAS 8 Score, median & 7.0 \\
\hline \multicolumn{2}{|l|}{ Adherence Level } \\
\hline Low & $16(25.8)$ \\
\hline Moderate & $25(40.3)$ \\
\hline High & $21(33.9)$ \\
\hline
\end{tabular}

Table 2. Internal consistency (Cronbach's alpha) for IPQ-R dimensions

\begin{tabular}{|c|c|}
\hline Dimensions & Cronbach's Alpha ( $\boldsymbol{\alpha})$ \\
\hline Timeline (Acute/Chronic) & 0.622 \\
\hline Consequences & 0.781 \\
\hline Timeline Cycle & 0.720 \\
\hline Personal Control & 0.575 \\
\hline Treatment Control & 0.499 \\
\hline Illness Coherence & 0.717 \\
\hline Emotional Representation & 0.868 \\
\hline Identity & 0.740 \\
\hline Cause & 0.795 \\
\hline
\end{tabular}


Table 3. Test-Retest Reliability using Spearman's Rank Correlation Coefficient $\left(r_{\mathrm{s}}\right)$ for IPQ-R dimensions

\begin{tabular}{|c|c|}
\hline Dimensions & $\begin{array}{c}\text { Spearman's Rank Correlation Coefficient }(\boldsymbol{r}) \\
\mathbf{( N}=\mathbf{1 3})\end{array}$ \\
\hline Timeline (Acute/Chronic) & $0.860(\mathrm{p}<0.001)$ \\
\hline Consequences & $0.973(\mathrm{p}<0.001)$ \\
\hline Timeline Cycle & $0.982(\mathrm{p}<0.001)$ \\
\hline Personal Control & $0.966(\mathrm{p}<0.001)$ \\
\hline Treatment Control & $0.893(\mathrm{p}<0.001)$ \\
\hline Illness Coherence & $0.917(\mathrm{p}<0.001)$ \\
\hline Emotional Representation & $0.977(\mathrm{p}<0.001)$ \\
\hline Identity** & $0.840(\mathrm{p}<0.001)$ \\
\hline Cause & \\
\hline Psychological & $0.927(\mathrm{p}<0.001)$ \\
Risk Factors & $0.981(\mathrm{p}<0.001)$ \\
Immunity & $0.928(\mathrm{p}<0.001)$ \\
\hline Accident or Chance & $0.924(\mathrm{p}<0.001)$ \\
\hline
\end{tabular}

Table 4. Association of Current INR with Illness Perception using Spearman's Rank Correlation Coefficient $\left(r_{s}\right)$ Analysis

\begin{tabular}{|c|c|c|}
\hline Dimensions & $\begin{array}{c}\text { Spearman's Rank } \\
\text { Correlation Coefficient }\left(\boldsymbol{r}_{\boldsymbol{s}}\right)\end{array}$ & p-value \\
\hline Timeline & -0.113 & 0.383 \\
\hline Consequences & 0.187 & 0.145 \\
\hline Timeline Cycle & 0.185 & 0.150 \\
\hline Personal Control & -0.022 & 0.863 \\
\hline Treatment Control & 0.227 & 0.076 \\
\hline Illness Coherence & -0.053 & 0.683 \\
\hline Emotional Representation & 0.278 & $0.028^{*}$ \\
\hline "Significant p-value & & \\
\hline
\end{tabular}

Table 5. Revised Illness Perception Questionnaire (IPQ-R) Total Score (median)

\begin{tabular}{|c|c|c|}
\hline Dimensions & $\begin{array}{c}\text { Total Score, median* } \\
\mathbf{( N = 6 2 )}\end{array}$ & Total Possible Score \\
\hline Timeline (Acute/Chronic) & 20.00 & $6-30$ \\
\hline Consequences & 20.00 & $6-30$ \\
\hline Timeline Cycle & 10.00 & $4-20$ \\
\hline Personal Control & 22.00 & $6-30$ \\
\hline Treatment Control & 18.00 & $5-25$ \\
\hline Illness Coherence & 16.00 & $5-25$ \\
\hline Emotional Representation & 15.00 & $6-30$ \\
\hline Identity** & 4.00 & $0-14$ \\
\hline Cause & 16.00 & $6-30$ \\
\hline Psychological & 20.00 & $7-35$ \\
Risk Factors & 8.00 & $3-15$ \\
Immunity & 6.00 & $2-10$ \\
\hline Accident or Chance & "Higher Score indicate stronger beliefs of the concept. \\
\hline "Median number of symptoms attributed to AF. \\
\hline
\end{tabular}

AF were stronger than beliefs about treatment effectiveness. The high timeline (acute/chronic) score and consequences score among our patients indicated that they believed that $\mathrm{AF}$ is a chronic condition which can cause significant consequences. However, the low timeline cycle score indicated that they do not perceive AF as a cyclical and unpredictable illness. The moderate illness coherence score indicated that subjects held beliefs that they understood their AF illness partially. The low emotional representation score revealed that subjects are not affected emotionally by their AF and are able to cope well with their illness.

\section{Discussion}

The major findings in this study indicate that the translated Malay version of IPQ-R could be used as a valid and reliable measurement tool for the evaluation of illness perception among AF patient. This study showed an excellent test-retest reliability with Spearman's Rank Correlation Coefficient $\left(r_{s}\right)$ ranging from 0.860 to $0.982(p<0.001)$. This was supported further by an acceptable internal consistency value. In addition, the IPQ has not been previously tested upon AF patients in Malaysia with multi-ethnicity and diverse cultural backgrounds. It was the first study conducted in the country with great potential for future use and reference.

Several studies have consistently shown that patients' beliefs or perceptions about their illness are an important factor which may affect one's adherence to medication and consequently, influences health outcomes $[13,23,24]$. In terms of demographic comparison, the baseline characteristics of study participants were almost similar with another study on atrial fibrillation admissions conducted locally, which reported the mean age of patients in Malaysia affected by AF was 65 years old ( $\mathrm{SD} \pm 10.3$ ) with over half $(52.5 \%)$ being male patients. Among their subjects, $44 \%$ were Malays, $40 \%$ were Chinese and $16 \%$ were Indians [25].

In terms of education level, over half of the patients in this study completed secondary education. In comparison to a 2011 study conducted in the United States, most of the patients were graduates (30\%) [25]. Thus, the difference in education level may affect our population's AF beliefs or perceptions as compared to the population in the United States.

\section{Reliability of IPQ-R dimensions}

The original IPQ-R questionnaire, which was tested by MossMorris et al. on sample of patients with rheumatoid arthritis (RA), type II diabetes and asthma, was found to be reliable with good predictive validity and sensitivity [22]. Our study among Malaysian patients with AF showed acceptable internal consistency with Cronbach's alphas ranging from 0.499 to 0.868 .

Although a Cronbach's alpha ( $\alpha$ ) value of 0.7 was the recommended value for high reliability [26], several studies had also utilized the cutoff point of $\alpha \geq 0.5$ as acceptable with moderate reliability [22,27,28]. In our study, our Cronbach alpha's values for all dimensions were above 0.5 except for the treatment control dimension $(\alpha=0.499)$, which may be due to the small sample size $(n=62)$ used in our study. As internal consistency is actually a correlation coefficient, a sample size which is small may affect its results [29]. Another reason is that, a shorter scale may result in a lower Cronbach's alpha value as this value is rather sensitive to the number of items in the scale. In the present study, the treatment control dimension in the IPQ-R only had 5 items.

The relationship between illness perceptions and anti-coagulation (INR) control was investigated. There were neither differences nor association found between those with INR in range and those with INR out of range patients in terms of how they view their AF. However, a significant relationship was found between patients' INR with their emotional representation dimension. There is a positive correlation of patients' INR with their negative emotions triggered by AF. This indicates that patients who are more inclined to feel negative emotions due to AF have a tendency to overwarfarinize. This finding is supported by another study conducted by McCabe et al. in the United States among AF patients [17]. Collectively, it further aids identification of patients who are affected negatively by $\mathrm{AF}$ and helps to increase monitoring efforts to reduce the risk of overwarfarinizing them.

With regard to the relationship between illness perceptions and warfarin adherence level, we found that adherence level had neither differences nor association on how patients view their AF. This could be 
due to the fact that approximately $63 \%$ of our subjects had undergone AF counselling and $98 \%$ had undergone warfarin counselling.

\section{Revised illness perception questionnaire (IPQ-R) total score}

Patients in this study seemed to perceive their AF was due to accident or chance rather than classical risk factors, psychological or immunity causes. As compared to other established risk factors like dietary factors, smoking and lifestyle factors [30], most patients in this study did not agree that lifestyle risk factors play a leading role in their disease.

It was found that our patients perceived their AF rather differently compared to populations from other studies. In terms of AF control, our subjects held beliefs that they could personally control their AF better than relying on medications. This opposes the findings found in a study by McCabe, et al. In their study, it was found that their patients believed that they have weaker personal control over their $\mathrm{AF}$ as compared to relying on medication to control their AF. This difference is probably due to the fact that the study was conducted among patient's with recurrent symptomatic AF. Thus, their patients may perceive that they have lower personal control because despite maximal self-effort, they were still suffering from recurrence. Another explanation to our contradicting findings may be because Malaysians tend to fear western medication due to beliefs that it is associated with higher side effects [32].

Our population held stronger beliefs that $\mathrm{AF}$ is a chronic condition and it can cause significant consequences in their lives. This finding is in accordance with several other studies [19]. In the study conducted by Lane et al., at least half of their study subjects perceived AF as a serious condition and approximately $9 \%$ of them perceived it as 'very serious' [9]. However, unlike in McCabe and colleagues' study, the low timeline cycle score in our population indicated that they do not perceive AF as a cyclical and unpredictable disease. This is probably due to the fact that in McCabe and colleagues' study, most of their patients were suffering from recurrent AF whereas in our study, patients suffering from recurrent or symptomatic AF were not accounted for.

Similar to a previous study [17], our subjects perceived that they understood AF partially, but they are also not affected emotionally by their AF. Their moderate level of understanding and ability to make sense of their disease is able to help them cope with their AF cognitively and emotionally.

One of the limitations in this study was the small sample size. As a result, the findings may not be generalizable to the whole population. Hopefully, a study with a larger sample size can be recruited and future studies can be done to confirm the findings of this study in terms of illness (AF) perception. With this, clinicians may identify patients at risk, take steps to address their negative illness perceptions and help them achieve better clinical and health outcomes.

\section{Conclusion}

Illness perceptions are important in managing patients' health and clinical outcomes. The translated Malay version of the Revised-Illness Perception Questionnaire (IPQ-R) is a valid and reliable instrument which can be used to provide a quantitative assessment of illness beliefs as it illustrated acceptable test-retest reliability and validity. It can be administered to our fellow Malaysians that speak and comprehend only the Malay language. With this validated tool, illness perceptions from this population can be included in our future researches.
There was no relationship found between warfarin adherence and atrial fibrillation perception in this study. However, there is a positive correlation of patients' INR with their negative emotions triggered by AF. Thus, this finding may be important to identify patients at risk and to monitor them closely to reduce the risk of over-anticoagulation. Findings in this study also give a glimpse of insight into how our local population perceive their AF. Hopefully, this may help clinicians identify and address these illness perceptions as part of their care.

\section{Acknowledgement}

We would like to thank all the participants and other personnel who were involved in the study. This research has not received any funding.

\section{References}

1. Kupper N, van den Broek KC, Widdershoven J, Denollet J (2013) Subjectively Reported Symptoms in Patients with Persistent Atrial Fibrillation and Emotional Distress. Front Psychol p. 4.

2. Aronow WS (2002) Atrial fibrillation. Heart Dis Hagerstown Md 4: 91-101.

3. January CT, Wann LS, Alpert JS, Calkins H, Cigarroa JE, et al. (2014) 2014 AHA/ ACC/HRS Guideline for the Management of Patients With Atrial Fibrillation: A Report of the American College of Cardiology/American Heart Association Task Force on Practice Guidelines and the Heart Rhythm Society. Circulation 130: e199-e267.

4. Heart Disease and Stroke Statistics—2009 Update. Circulation 119: e21.

5. Atrial fibrillation part 1: pathophysiology. Practice Nursing 23: 1.

6. Lim CW, Kasim S, Ismail JR, Chye Chua NY, Najme Khir R, et al. (2016) Prevalence of atrial fibrillation in the Malaysian communities. Heart Asia 8: 62-66.

7. Kang Y, Bahler R (2004) Health-related quality of life in patients newly diagnosed with atrial fibrillation. Eur J Cardiovasc Nurs 3: 71-76.

8. Grönefeld GC, Lilienthal J, Kuck KH, Hohnloser SH (2003) Pharmacological Intervention in Atrial Fibrillation (PIAF) Study investigators. Impact of rate versus rhythm control on quality of life in patients with persistent atrial fibrillation. Results from a prospective randomized study. Eur Heart J 24: 1430-1436.

9. Lane D, Carroll D, Ring C, Beevers DG, Lip GY (2001) Mortality and quality of life 12 months after myocardial infarction: effects of depression and anxiety. Psychosom Med 63: 221-230.

10. Diefenbach MA, Leventhal H (1996) The common-sense model of illness representation: Theoretical and practical considerations. J Soc Distress Homeless 5: $11-38$.

11. Leventhal H (1984) Illness Representations and Coping with Health Threats.

12. Millar MG, Millar KU (1993) Affective and cognitive responses to disease detection and health promotion behaviors. J Behav Med 16: 1-23. [Crossref]

13. Güler SK, Güler S, Cokal BG, Gunes N, Yon Mİ, et al. (2017) Validation of the Revised Illness Perception Questionnaire in Turkish epilepsy patients and the effects of earthquake experience on perception of disease. Neuropsych Dis Treat 13: 551-556.

14. Protheroe J, Fahey T, Montgomery AA, Peters TJ (2000) The impact of patients' preferences on the treatment of atrial fibrillation: observational study of patient based decision analysis. BMJ 320: 1380-1384. [Crossref]

15. Howitt A, Armstrong D (1999) Implementing evidence based medicine in genera practice: audit and qualitative study of antithrombotic treatment for atrial fibrillation. BMJ 318: 1324-1327. [Crossref]

16. Ross S, Walker A, MacLeod MJ (2004) Patient compliance in hypertension: role of illness perceptions and treatment beliefs. J Hum Hypertens 18: 607-613.

17. McCabe PJ, Barnason SA, Houfek J (2011) Illness beliefs in patients with recurrent symptomatic atrial fibrillation. Pacing Clin Electrophysiol PACE 34: 810-820.

18. Weinman J, Petrie KJ, MossMorris R, Horne R (1996) The illness perception questionnaire: A new method for assessing the cognitive representation of illness. Psychol Health 11: 431-445.

19. Moss-Morris R, Weinman J, Petrie K, Horne R, Cameron L, et al. (2002) The Revised Illness Perception Questionnaire (IPQ-R). Psychol Health 17: 1-16.

20. WHO (2007) Process of translation and adaptation of instruments. 
21. Morisky DE, Ang A, Krousel-Wood M, Ward HJ (2008) Predictive validity of a medication adherence measure in an outpatient setting. J Clin Hypertens Greenwich Conn 10: 348-354. [Crossref]

22. Al-Qazaz HK, Hassali MA, Shafie AA, Sulaiman SA, Sundram S, et al. (2010) The eight-item Morisky Medication Adherence Scale MMAS: translation and validation of the Malaysian version. Diabetes Res Clin Pract 90: 216-221. [Crossref]

23. Brink E, Alsén P, Cliffordson C (2011) Validation of the Revised Illness Perception Questionnaire (IPQ-R) in a sample of persons recovering from myocardial infarction-the Swedish version. Scand J Psychol 52: 573-579.

24. Giannousi Z, Manaras I, Georgoulias V, Samonis G (2010) Illness perceptions in Greek patients with cancer: a validation of the Revised-Illness Perception Questionnaire. Psychooncology 19: 85-92.

25. Freestone B, Rajaratnam R, Hussain N, Lip GYH (2003) Admissions with atrial fibrillation in a multiracial population in Kuala Lumpur, Malaysia. Int J Cardiol 91: 233-238.

26. Pallant J (2003) SPSS Survival Manual: A Step-by-Step Guide to Data Analysis Using SPSS for Windows (Versions 10 and 11); [Applies to SPSS for Windows up to Version 11]. Reprinted. Buckingham: Open Univ. Press.
27. Norfazilah A, Samuel A, Law P, A Ainaa, A Nurul, et al. (2013) Illness perception among hypertensive patients in primary care centre UKMMC. Malays Fam Physician 8: 19-25. [Crossref]

28. SPSS survival manual: a step by step guide to data analysis using IBM SPSS (2013) Aust NZ J Publ Heal.

29. SPSS Explained: [2nd Edn] (Paperback) - Routledge.

30. Penning-van Beest FJA, Geleijnse JM, van Meegen E, Vermeer C, Rosendaal FR, et al. (2002) Lifestyle and diet as risk factors for overanticoagulation. J Clin Epidemiol 55: 411-417. [Crossref]

31. Taylor EC, O’Neill M, Hughes LD, Moss-Morris R (2018) An illness-specific version of the Revised Illness Perception Questionnaire in patients with atrial fibrillation (AF IPQ-R): Unpacking beliefs about treatment control, personal control and symptom triggers. Psychol Health 33: 499-517.

32. Muhamad M, Merriam S, Suhami N (2012) Why Breast Cancer Patients Seek Traditional Healers. Int J Breast Cancer 2012: 689168. [Crossref]

Copyright: $@ 2019$ Tan Su Ann S. This is an open-access article distributed under the terms of the Creative Commons Attribution License, which permits unrestricted use, distribution, and reproduction in any medium, provided the original author and source are credited. 